\title{
Time and Communication
}

\author{
KRISTÓf NYíri
}

My main thesis in this paper, for which I will argue in section 3, is that with the mobile phone, time has become personalized. It is not just our perception of time that has changed, nor indeed merely our way of talking about time. What has changed is, in fact, the nature of time. Wittgensteinian received wisdom of course would not allow one to keep a straight face when mentioning the nature of time, or even when using the substantive "time" in earnest. I believe the received wisdom is wrong; an alternative philosophical strategy applicable to the problem of time is outlined in section 1.

\section{Philosophical preliminaries}

It should be pointed out that though his therapeutic tone pervades the 193235 lectures and dictations, and is dominant in the Philosophical Investigations (Kaspar and Schmidt 1992; Grundy 2005, 97; Reichenberger 2005), Wittgenstein himself did sometimes refer to time in a different key. In contrast to the position that puzzlement about the nature of time arises from a grammatical confusion (Wittgenstein 1979, 15; Wittgenstein 1958, 6; Wittgenstein 1953, §§89f.), he also made remarks suggesting that genuine issues might pertain to the phenomenon of time; that there might be room for exploration and insight here. According to one such remark, written in 1937 and still being experimented with in 1942/43 (in the text that was to become Part I of the Philosophical Investigations): "That times occur to us in coincidence with the clock; that we can estimate the time; is one of the reasons why what the clock measures, the time, is so important". ${ }^{1}$ Or recall the remark, written in 1941: "could we talk about minutes and seconds, if we had no sense of time; if there were no clocks ...; if there did not exist all the connexions that give our measures of time meaning and importance?"2

1 "Dass uns die Zeiten übereinstimmend mit der Uhr einfallen; dass wir die Zeit schätzen können; ist ein Grund, warum, was die Uhr misst, die Zeit, so wichtig ist", Wittgenstein 2001, 517f.

2 Cf. Wittgenstein 1978, 382. The sentence as printed there has "hours" instead of "minutes"; the same error occurs in the German editions as well. I am indebted to István Danka for alerting me to this lapse. 
On the other hand, when jotting down the remarks "This is the similarity of my treatment with relativity-theory, that it is so to speak a consideration about the clocks with which we compare events" (Wittgenstein 1978, 330) and "Einstein: how a magnitude is measured is what it is" ${ }^{3}$ Wittgenstein clearly saw himself as staying within the confines of grammar-compare his remark, written in 1937: "Du vergißt, was //glaube ich// Einstein //wie ich vermute// die Welt gelehrt hat: daß die Methode //Art \&Weise// der Zeitmessung zur Grammatik der Zeit-Ausdrücke gehört” (Wittgenstein 2000: MS 119). Of course the similarity between Einstein's approach and that of Wittgenstein soon breaks down. Where Wittgenstein warned against moving beyond the grammar of everyday language, Einstein sought to modify the everyday world-view embodied in our everyday grammar. As Wittgenstein said in 1935: "There is no trouble at all with primitive languages about concrete objects.... A substantive in language is used primarily for a physical body, and a verb for the movement of such a body.... We might say that it is the whole of philosophy to realize that there is no more difficulty about time than there is about this chair" (Wittgenstein 1979, 119). By contrast, Einstein certainly saw difficulties both with time and with primitive languages, and was intent on solving the former by clarifying the latter. As he wrote in 1934: "[ $t]$ he whole of science is nothing more than a refinement of everyday thinking" (cf. Miller 1984, 13).

How can one avoid making time seem a "queer thing" (Wittgenstein 1958, 6), and still build up meaningful discourse about what time is? The philosophical strategy I believe to be the most promising here is to regard time as a kind of theoretical entity, in the specific sense Wilfrid Sellars gave to this term. The point where Sellars' view of the nature of theories differs most significantly from that of, say, Carnap, Reichenbach, and Hempel, is his conviction that science is "continuous with common sense". As he puts it: "the ways in which the scientist seeks to explain empirical phenomena are refinements of the ways in which plain men, however crudely and schematically, have attempted to understand their environment ... since the dawn of intelligence" (Sellars 1963, 181-183). It is within the framework of everyday observational discourse that certain unobservable entities are first postulated, entities in terms of which certain properties of observable events become explainable. Now according to Sellars, time is just such a postu-

3 Written in 1929, and included in The Big Typescript, see Wittgenstein 2005: 208 and 488 for two different translations; the second is the correct one. 
lated entity, with "events in Time (or Space-Time) as metrical abstractions grounded in the reality of changing substances" (Sellars 1975, 282). There emerge "rules for coordinating statements concerning empirically ascertainable metrical relations between episodes pertaining to the things of everyday life and science, with statements locating these episodes, relatively to other episodes, in time, that is, with statements having the characteristic syntax of statements 'about time'" (Sellars 1962, 551 f.). The advance of science, the physical theory of time, will tell us what time is (Sellars 1962, 593), but this advance has been underway all through the cultural evolution of humanity, from primitive thought through Plato, Aristotle, and Augustine, to modern and contemporary philosophy and physics. ${ }^{4}$

A great advantage of the specifically Sellarsian interpretation of time as a theoretical entity is that it allows for an amalgamation of social time, or time as a social construct, with astronomical time, or time as a construct of the physical sciences. The classic statement as to the originally social nature of time of course comes from Durkheim. It is clear, Durkheim wrote, that those indispensable fixed points with respect to which all things are temporally organized are the products of social life; that it is the periodicity of rites, feasts, public ceremonies, to which the division into days, weeks, months, years, etc. corresponds. Time, as opposed to duration, is time as lived by the group-social time; it is time, as Durkheim puts it, "tel qu'il est objectivement pensé par tous les hommes d'une même civilisation" (Durkheim 1912, Intr., sect. II). One and the same civilization-it should be stressed that this is a dynamic, rather than static, notion. Let me quote at some length the decisive sequel to Durkheim's argument, by Sorokin and Merton (1937):

The local time system varies in accordance with the differences in the extent, functions, and activities of different groups. With the spread of interaction between groups, a common or extended time system must be evolved to supersede or at least to augment the local time systems.... The final common basis was found in astronomical phenomena ... Thus, the social function of time reckoning and designation as a necessary means of coordinating social activity was the very stimulus to astronomical time systems ...

4 As Whitrow (1961:58) puts it: "out of man's primeval awareness of rhythm and periodicity there eventually emerged the abstract idea of world-wide uniform time". 
Interaction between groups, as well as the coordination of social activities, essentially involve communication. And indeed there is an intrinsic connection between time and communication, whichever meaning of the latter term we focus on. "Communication" in its original, archaic sense means participation. Echoing Dewey (1916) and Heidegger (1927), this is the sense Carey singled out when describing the "ritual" view of communication. The ritual view, he wrote, "exploits the ancient identity and common roots of the terms 'commonness', 'communion', 'community', and 'communication'. A ritual view of communication is directed not toward the extension of messages in space but toward the maintenance of society in time ..." (Carey 1975). In another sense, communication of course means transportation-moving people and goods through space, in real time. And then there is communication in the sense of conveying information. It is the connection of time with communication in this latter sense that constitutes the topic of my paper. The connection can be seen in two broad perspectives.

First, the communication of temporal information-communicating time. My argument in section 3 will be about communicating time in everyday life; at the present juncture, let me insert a brief reference to communicating time as a scientific issue. The reference of course is, once more, to Einstein, for whom the problem of synchronizing clocks at a distance was the starting point on the road leading to the special theory of relativity. Nor was this issue for Einstein, as has been brilliantly demonstrated by Galison (2003), an abstractly scientific one. The young patent office clerk in Bern had dutifully evaluated dozens of submissions having to do with the distant synchronization of clocks by electric means before hitting on the revolutionary thesis of his 1905 paper on electrodynamics.

The second perspective is about the impact of communication technologies on our notions of time - and, with that, on the formation of the theoretical entity time itself. This is the perspective I shall pursue in section 2.

\section{From cyclic time to timeless time}

According to a periodization germinating from McLuhan's Toronto circle, the history of the technology of communication can be divided into the following main phases: 1 . primary orality; 2 . literacy; 3 . the typographic phase (printing); 4. "secondary orality", given rise to by electronic information processing and transfer. Elaborated, most notably, by Havelock (1963), Goody and Watt (1963) and Ong (1982), this periodization has for some 
time been rather widely accepted. I myself have adhered to it (cf. Nyíri 1991 and Nyíri 1992), until about the time I began working on my "The Picture Theory of Reason" (Nyíri 2001). Since then, I have realized that a more finegrained set of distinctions is called for. Currently, I would suggest something like the following series of divisions: 1 . Mimetic communication, based on what has been referred to as "the emergence of the most basic level of human representation, the ability to mime, or re-enact, events" (Donald 1991, 16). Not only do we have good grounds to assume that language first emerged as a visual sign system, but clearly it today still retains a basic dimension of mimetic gestures. 2 . The culture of primary orality, where words are exclusively spoken or heard, with the knowledge society possesses stored in easily recalled formulae, memorized through constant repetition of authoritative texts. 3. Pictorial communication, ranging from the earliest cave paintings through ancient pictographs, and through medieval and modern drawings, to photography, and on to twentieth-century iconic symbols (today, conspicuously, icons on digital displays). 4. Ideographs. 5. Syllabic and alphabetic writing. 6. Typography. 7 . The age of secondarily oral communication, within which again several phases and dimensions must be distinguished: telegraphy, representing a step away from the silence of writing towards the world of sounds not because it involved clicks and clacks just as it did dots and dashes, but because it gave rise to an elliptic style reminiscent of spoken rather than written language; the telephone; the movie, both in its silent and sound film phases; radio broadcasting; television; and the various sound and video recording devices. 8. Computer-mediated communication, creating a kind of secondary literacy with e-mail (and its cousins instant messaging and mobile SMS), a return to writing in the age of secondary orality; creating, also, a network of users exchanging multimedia documents.

What effect do these different modes of communication have on the evolving concept of time? Here the language of gestures provides a truly fertile initial medium. Gestures are movements, the meanings conveyed by them are created visibly in time. They necessarily create the experience both of "before" and "after", as well as the experience of time consisting of extended intervals, the latter experience leading, say, to the Stoics' idea of the "broad" present (Sorabji 1983, 25), or to James' elaboration of the notion of "the specious present" (James 1890, 608 f.), with this notion having interesting echoes in Wittgenstein's middle period (Wittgenstein 1975, 98 and Wittgenstein 2005, 351). Miming, that is re-enacting, events must also generate a rudimentary consciousness of the difference between the present and 
the past-between what is in fact lived through, and what is only remembered. The experience of memory provides one of the main inspirations for the theoretical construct time. However, for this experience to become fully conscious, something like a verbal language must first emerge. In the case of autobiographical memory, it is with the development of linguistic skills that so-called childhood amnesia gradually diminishes, and first recollections arise (Draaisma 2004, 24 f.). Similarly with primitive group memory, which is embodied in myths and preserved through the basic information storage and retrieval activity of primarily oral societies: the recitation, that is repetition, of texts. To repeat is to re-live: time in the medium of primary orality is experienced as cyclic, rather than as linear. And it is of course a cyclic view of time that the daily movement of the sun, the changes of the moon, the seasons of the year, and the succession of generations in the animate world suggest. The idea of linear time is a culturally subordinate construct, one which did not become dominant prior to the age of the printing press.

Jan Assmann provides a masterly summary (Assmann 1999, 27-38) of the simultaneous, but unequal, presence of the cyclic and the linear views in medieval Christianity (with the Church partaking in the sacred linear history leading to salvation, while events here in this world followed a cyclic pattern), in ancient Mesopotamia (with occasional attempts at retrospective political chronicles), and indeed in Egypt (where the construction of king lists represented rare and insignificant episodes within an overwhelmingly cyclic world view). The Egyptians did have a linear writing system just as the Mesopotamians did. However, the educated Egyptian was, also, immersed in a world of pictures, a world of images and ideographs (hieroglyphs). Now it is of course well-known that what these pictures depict conveys a notion of time recurring, or standing still. Also, the canonical style of Egyptian art, unchanging over thousands of years (Assmann 1992, 171-174), suggested and indeed upheld an idea of immutable time, where contact with the past meant repetition, not continuation. ${ }^{5}$ But the question we must here ask is whether it may not lie in the very nature of pictorial communication to give rise to a halting, as opposed to a sequential, view of temporality. And one

5 "Die Kanonisierung der Bildkunst ... steht im Dienste der Wiederholbarkeit, nicht der Anschließbarkeit", and similarly with texts: "Texte werden kopiert und variiert, aber sie werden nicht eigentlich interpretiert" (Assmann 1992, 177, 175). Yet here, too, one should pay heed to Assmann's warning against an all too uniform view of ancient Egypt: "Man darf sich das Weltbild einer mehrtausendjährigen und vielschichtigen Kultur nicht zu monolithisch vorstellen” (Assmann 1975, 20). 
way to argue for this would be to point out that the handed-down is more powerful in pictorial than in textual form: a culture where the image dominates over text might well be more acquiescent, less prone to initiate changes in the pattern of events, than one in which text rules over the image.

On the other hand, it should be stressed that even though, as Wittgenstein convincingly demonstrated (Wittgenstein 1953, §22), isolated pictures are often ambiguous, a series of pictures, or a moving image, can very well be unequivocal, and can tell a story, i.e. recount events happening in time. Indeed one of the most interesting extended discussions by Wittgenstein on time (Wittgenstein 1958, 104-109), dealing with the question of "how a child might be trained in the practice of "narration of past events", begins with the introduction of a pictorial language involving two sequences of images running in parallel to each other. One sequence is the "sun series", representing the passage of time during the day, the other the "life pictures", showing the activities of a child. The two rows of pictures, when properly correlated, "tell the story of the child's day". Alternatively, the sun series can be replaced by writing a number against each life picture indicating the hour on the dial of a clock in the nursery. Interestingly, this pictorial training of the child does not seem to proceed beyond the boundaries of a single day. The sun completes its daily round, as does the hour hand of the clock; the picture series suggest a cyclic, rather than a linear, notion of time.

Syllabic and alphabetic systems, with writing and reading proceeding from top to bottom, right to left, or left to right, in a definite direction (if we skip the boustrophedon, "as the ox ploughs", early variants), obviously create a minimum experience of time being linear and having a direction. ${ }^{6}$ But the temporal world of manuscript cultures - think of Greece, think of the European Middle Ages-is still overwhelmingly cyclic. There are two broad reasons for this. First, there was a residual orality resulting from the phenomenon of reading aloud (typical before the advent of easily followable printed texts), with written lines, ultimately, still experienced as a fleeting succession of sounding syllables; secondly, text corruption was a common by-product of manual copying. The older a manuscript, the more reliable the text: there is decay, and a feeling that one should return to the beginnings.

With the advent of the printing press, a radical change occurs. Every new edition produces identical, or indeed improved-corrected—texts. It was

6 While reading a linear text is a unidirectional process, looking at pictures involves to-and-fro scanning. This might be another cause for pictorial communication not engendering a linear notion of time. 
the fully developed age of the printed text, beginning with the seventeenth century, in which the idea of linear time became victorious. Newton's vision of the constant linear flow of time, and of course Locke's enthusiastic endorsement of that vision, would not have been imaginable without the suggestion of a "constant and regular succession of ideas" (Essay, II, xiv, 12) created by following the printed line. This was the age, too, in which the notion of progress, and modern historical consciousness, emerged. As Elizabeth Eisenstein wrote: "Before trying to account for an 'idea' of progress we might look more closely at the duplicating process that made possible not only a sequence of improved editions but also a continuous accumulation of fixed records.... the communications shift [precedes] ... the beginning of a modern historical consciousness ... by a century or more. The past could not be set at a fixed distance until a uniform spatial and temporal framework had been constructed" (Eisenstein 1979, vol. I, 124 and 301). Or to quote Sven Birkerts' memorable formulation: "our sense of the past ... is in some essential way represented by the book and the physical accumulation of books in library spaces. In the contemplation of the single volume, or mass of volumes, we form a picture of time past as a growing deposit of sediment; we capture a sense of its depth and dimensionality" (Birkerts 1994, 129).

Historical consciousness, the ability, as J.H. Plumb puts it, "to see things as they were in their own time", "the consciousness of a different past", the "wish to understand the past in its own terms" (Plumb 1969, 82 and 118f.), did not, then, fully emerge before the seventeenth century. And after less than three hundred years, with the rise of telegraph news reporting, it had already begun to erode. Historical consciousness presupposes a definite point of view in time. Until the 1860s, the column reigned over the news even in the daily paper; there was a temporal perspective the newspaper conveyed. But then the daily paper became, to quote McLuhan, "a mosaic of unrelated scraps in a field unified by a dateline. Whatever else there is, there can be no point of view in a mosaic of simultaneous items" (McLuhan 1964, 249).

In a much more tangible way, too, the experience of time was changed by the telegraph. Precise longitude determination and global mapmaking initially depended on the transportation of accurate timekeepers. After 1866, when the first transatlantic cable was successfully laid, long-distance synchronization of clocks became possible. By 1880, every inhabited continent was connected (Galison 2003, 132-144). Local times came to be elements within the overall framework of global time; there emerged the practice of almost real-time communication between people belonging to differ- 
ent time zones. The "mixing of tenses" bemoaned by Castells (1996, 433) began with telegraphy, the first medium which allowed a separation of the movement of information from the movement of people. The second such medium was telephony, with distant communication becoming actually realtime, and with the narrow broadband of telegraphy giving way to the much wider broadband of live human voice.

In 1895 the Lumière brothers presented their cinematograph. With that, an extremely powerful new metaphor for the flow of time came into being (Draaisma 2004, 57ff.). Bergson made fundamental use of it; Wittgenstein, in the early 1930s, was infatuated with it (Reichenberger 2005, 255). In Creative Evolution there is an argument spanning some 40 pages (Bergson 1911, 304-345), in which the cinematograph simile ("the film of the cinematograph unrolls, bringing in turn the different photographs of the scene to continue each other") is deployed to explain our inability to recognize real becoming behind a series of mental snapshots, to dissolve Zeno's paradox of the flying arrow, to provide a context for the immutable eidos, to highlight both the parallels and the differences between modern and ancient science, and of course to plead once more for the Bergsonian notion of durée: "if time is not a kind of force, why ... is not everything given at once, as on the film of the cinematograph?”. Wittgenstein seems to have read Bergson, and he, too, was impressed by the difference of the series of pictures existing, on the one hand, synchronously on celluloid, and on the other, creating a narrative in time on the screen: "If I compare the facts of immediate experience with the pictures on the screen and the facts of physics with pictures in the film strip, on the film strip there is the present picture and past and future pictures. But on the screen, there is only the present" (Wittgenstein, 1975, 83).

Then there is, in the silent film, the effect of verbal language being subordinated to the secondary role of mere captions. The poet, playwright, and film critic Béla Balázs, in a book published in 1924 (Der sichtbare Mensch, "The visible man"), made the following observation: "In film ... speaking is a play of facial gestures and immediately visual facial expression. They who see speaking, will learn things very different from those who hear the words". Balázs expresses his belief that film will bring back "the happy times" when, in contrast to the times "since the spread of the printing press [when] the word came to be the main bridge between human beings", "it was still allowed for pictures to have a 'theme', an 'idea', because ideas did not always first appear in concepts and words, so that painters would only subsequently provide illustrations for them with their pictures"(Nyíri 1999, 7f.). The pure 
pictoriality of the silent film was soon supplanted by the sound film, the first multimedia. But whether silent or sound, the experience of time given rise to by film was not the linear one suggested by written, especially printed, language.

The more obvious influences of film on the experience of time are wellknown. The techniques of slow motion, fast motion, or running the film backwards create entirely new temporal impressions. Also, scenes alternate. With television, especially with cutting becoming ever faster, the breaking up of time as an ordered sequence continues. ${ }^{7}$ And with satellite channels, "TV's electronic time zones are competing increasingly with ... our internal biological clocks to determine our sense of time" (Ofield 1994, 593). What began with telegraphy, and continued with shortwave radio and longdistance telephony - the juxtaposing of different local times-went yet a step further with global television. The final step, of course, was the emergence of computer networks.

Computers transformed our experience of time even before world-wide computer networks were built. In one of the founding analyses of the topic, Bolter argued that, for the computer programmer, time becomes finite, discrete, and - think of loops-cyclic (Bolter 1984, 100-123). But let us note that even for everyday users, certain time-related phenomena are changed. Word processing has a special significance here. The spoken word is flexible, elastic, but vanishes in the moment of speaking. Written language, and to an even greater extent, printed language, are enduring but rigid. A text that is stored in the computer, in contrast, is preserved, but changeable as well. The text called up from the memory of the computer is always simultaneous, lacking in all history. Age-old documents preserved in the computer carry no mark of temporality. Images called up from a CD-ROM or downloaded from the network might carry indications of their history; yet in their digitized form they belong to the here-and-now, with no difference whatsoever between original and copy. Clearly, this environment of timeless documents cannot remain without influence on our sense of time.

Simple word-processing, global computer networks, and the world of digital multimedia documents all contribute, then, to the emergence of what Castells calls timeless time. As he puts it: "linear, irreversible, measurable, predictable time is being shattered in the network society ... we are not just witnessing a relativization of time according to social contexts or alterna-

7 For a discussion from a complementary point of view, see Steininger 2005. 
tively the return to time reversibility ... The transformation is more profound: it is the mixing of tenses to create a forever universe ..., not cyclical but random" (Castells 1996, 433). However, as I attempt to show in the concluding section of this paper, the truly fundamental transformation in communications today - the triumphant progress of the mobile phone-does not further aggravate, but much rather alleviates the condition of timeless time.

\section{Time and the mobile phone}

Back in 1934, Lewis Mumford noted that what is effected by "our closer time co-ordination and our instantaneous communication" is "broken time and broken attention" (Mumford 1963, 272). By contrast, I believe that the mobile phone gives rise to a new synthesis of what Mumford referred to as "mechanical time" and "organic time". ${ }^{8}$

At the very beginning of Technics and Civilization Mumford gave a list of "the critical instruments of modern technology" (Mumford 1963, 4). The first two items on this list are the clock and the printing press. Now the two technical inventions whose significance is most plausibly paralleled by that of the mobile phone are the portable book and the portable clock. The portable hand-held book was an innovation, in 1501, of publisher Aldus Manutius. What this innovation enabled was communication, albeit unidirectional, with the absent author, anytime, anywhere; and access to information anytime, anywhere, as long as that information was contained in the books one carried around. The emergence of the portable clock, and the beginnings of the transition from the portable clock to the watch, took place over the course of the fifteenth century. The mechanical clock itself was invented in the thirteenth century. At first, it had no dial but it did strike the hours-it was in fact, as Landes puts it, an "automated bell" (Landes 2000, 81)—communicating time within the space of the monastery, or in the public space of the medieval town. The fourteenth century saw the spread of bell towers. Urban society increasingly depended on these, the "striking of the bells brought a new regularity into the life of the workman and the merchant" (Mumford

8 "[M] echanical time is strung out in a succession of mathematically isolated instants ... [While] mechanical time can ... be speeded up or run backward, like the hands of a clock or the images of a moving picture, organic time moves in only one direction - through the cycle of birth, growth, development, decay, and death" (Mumford 1963: 16). 
1963, 14). With the portable clock, public time could also be kept privately.

By the nineteenth century, the regularity dictated by public time could no longer be experienced but as a tyranny of fixed schedules. As Georg Simmel wrote in his famous paper "Die Großstädte und das Geistesleben" in 1903, "The relationships and affairs of the typical metropolitan usually are so varied and complex that without the strictest punctuality in promises and services the whole structure would break down into an inextricable chaos. ... If all clocks and watches in Berlin would suddenly go wrong in different ways", Simmel continued, "all economic life and communication of the city would be disrupted for a long time. In addition, ... long distances ... make all waiting and broken appointments result in an ill-afforded waste of time. Thus, the technique of metropolitan life is unimaginable without the most punctual integration of all activities and mutual relations into a stable and impersonal time schedule". ${ }^{9}$

By the last decades of the twentieth century, the rule of the clock became simply impractical in many domains of decentralized mass society, i.e. postmodern society. As Ling $(2004,62)$, in reference to Beniger (1986), puts it: "The demands for rapid and geographically dispersed coordination of small groups became more acute due to the rise of transportation systems and the differentiation of social functions." It appears that in the postmodern world, the need for the possibility of frequent re-scheduling was there even before the mobile phone, the instrument par excellence for changing schedules while on the move, appeared on the scene. ${ }^{10}$ To a considerable degree, the mobile actually took over the functions of the clock. The co-ordination of social activity today relies, in no small measure, on mobile negotiation, rather than on keeping pre-defined schedules (Ling and Yttri 2002, 143f.). A different way of synchronizing activities has emerged: within the overall framework of fixed public time, windows of personalized time are opening up. In the constitution of the theoretical entity time, the building-block of Einstein's situation-bound relative time there is now joined by the buildingblock of personalized time.

9 Simmel 1997, 177f. In the sentence "In addition ..." I had to modify the translation "would make all waiting" to "make all waiting". Simmel here is not continuing the speculation about what would happen if clocks went wrong, but is making a straightforward observation to the effect that since in the metropolis one has to travel longish distances to keep appointments, non-punctuality is all the more unpleasant.

10 "The mobile phone breaks the flow of information away from the scheduling necessary to ensure coordination of journeys" (Townsend 2000: 96). 


\section{Literature}

Assmann, Jan 1975 Zeit und Ewigkeit im alten Ägypten: Ein Beitrag zur Geschichte der Ewigkeit, Heidelberg: Carl Winter Universitätsverlag.

- 1992 Das kulturelle Gedächtnis: Schrift, Erinnerung und politische Identität in frühen Hochkulturen, München: C.H. Beck.

- 1999 Ägyten: Eine Sinngeschichte, Frankfurt/M.: Fischer Taschenbuch Verlag.

Beniger, James R. 1986 The Control Revolution: Technological and Economic Origins of the Information Society, Cambridge, MA: Harvard University Press.

Bergson, Henri 1911 Creative Evolution, transl. by Arthur Mitchell, New York: Henry Holt.

Birkerts, Sven 1994 The Gutenberg Elegies: The Fate of Reading in an Electronic Age, Boston: Faber and Faber.

Bolter, J. David 1984 Turing's Man: Western Culture in the Computer Age, Chapel Hill: University of North Carolina Press.

Carey, James W. 1975 "A Cultural Approach to Communication”, Communication 2, 1-22.

Castells, Manuel 1996 The Rise of the Network Society, Oxford: Blackwell.

Dewey, John 1916 Democracy and Education: An Introduction to the Philosophy of Education, New York: Macmillan.

Donald, Merlin 1991 Origins of the Modern Mind: Three Stages in the Evolution of Culture and Cognition, Cambridge, MA: Harvard University Press.

Draaisma, Douwe 2004 Why Life Speeds Up As You Get Older: How Memory Shapes Our Past, Cambridge: Cambridge University Press.

Durkheim, Emile 1912 Les formes élémentaires de la vie religieuse, Paris: Alcan.

Eisenstein, Elizabeth 1979 The Printing Press as an Agent of Change: Communications and Cultural Transformations in Early-Modern Europe, Cambridge: Cambridge University Press.

Galison, Peter 2003 Einstein's Clocks, Poincarés Maps: Empires of Time, London: Hodder and Stoughton.

Goody, Jack and Watt, Ian 1963 "The Consequences of Literacy”, Comparative Studies in Society and History 5, 304-345. 
Grundy,W.P. 2005 "Wittgenstein, Spengler and Time”, in: Friedrich Stadler and Michael Stöltzner (eds.), Time and History: Papers of the 28th International Wittgenstein Symposium, Kirchberg am Wechsel: ALWS, 96-98.

Heidegger, Martin 1927 Sein und Zeit, Halle an der Saale: Niemeyer.

Havelock, Eric 1963 Preface to Plato, Cambridge, MA: Harvard University Press.

James, William 1890 The Principles of Psychology, New York: Henry Holt.

Kaspar, Rudolf E. and Schmidt, Alfred 1992 "Wittgenstein über Zeit", Zeitschrift für philosophische Forschung 46, 569-83.

Landes, David S. ${ }^{2} 2000$ Revolution in Time: Clocks and the Making of the Modern World, Cambridge, MA: Belknap Press.

Ling, R. 2004 The Mobile Connection: The Cell Phone's Impact on Society, Amsterdam: Elsevier.

Ling, R. and Yttri, Birgitte 2002 "Hyper-Coordination via Mobile Phones in Norway", in: James E. Katz and Mark Aakhus (eds.), Perpetual Contact: Mobile Communication, Private Talk, Public Performance, Cambridge: Cambridge University Press, 139-169.

McLuhan, Marshall 1964 Understanding Media: The Extensions of Man, New York: McGraw-Hill.

Miller, Arthur I. 1984 Imagery in Scientific Thought: Creating 20th-Century Physics, Boston: Birkhäuser.

Mumford, Lewis ${ }^{2} 1963$ Technics and Civilization, New York: Harcourt Brace \& Company.

Nyíri, Kristóf [J. C.] 1991 "Historisches Bewußtsein im Informationszeitalter", in: Dieter Mersch and Kristóf Nyíri (eds.), Computer, Kultur, Geschichte: Beiträge zur Philosophie des Informationszeitalters, Wien: Edition Passagen, 65-80.

- 1992 Tradition and Individuality: Essays, Dordrecht: Kluwer.

- 1999 "From Palágyi to Wittgenstein: Austro-Hungarian Philosophies of Language and Communication, in: Kristóf Nyíri and Peter Fleissner (eds.), Philosophy of Culture and the Politics of Electronic Networking, vol. 1, Innsbruck-Wien: Studien Verlag / Budapest: Áron Kiadó, 1-11.

- 2001 "The Picture Theory of Reason", in: Berit Brogaard and Barry Smith (eds.), Rationality and Irrationality, Wien: öbv-hpt, 242-266.

Ofield, Jack 1994 Television", in: Samuel L. Macey (ed.), Encyclopedia of Time, New York: Garland, 592-594.

Ong, Walter J. 1982 Orality and Literacy: The Technologizing of the Word, London: Methuen. 
Plumb, J.H. 1969 The Death of the Past, London: Macmillan.

Reichenberger, Andrea A. 2005 “'Was ist Zeit?' Wittgensteins Kritik an Augustinus kritisch betrachtet”, in: Friedrich Stadler and Michael Stöltzner (eds.), Time and History: Papers of the 28th International Wittgenstein Symposium, Kirchberg am Wechsel: ALWS, 253-255.

Sellars, Wilfrid 1962 "Time and the World Order", in: Herbert Feigl and Grover Maxwell (eds.), Minnesota Studies in the Philosophy of Science, vol. III, Minneapolis: University of Minnesota Press, 527-616.

- 1963 "Empiricism and the Philosophy of Mind", in: Wilfrid Sellars, Science, Perception and Reality, London: Routledge \& Kegan Paul, 127-196.

- 1975 “Autobiographical Reflections”, in: Hector-Neri Castañeda (ed.), Action, Knowledge and Reality: Critical Studies in Honor of Wilfrid Sellars, Indianapolis: Bobbs-Merrill, 277-93.

Simmel, Georg 1997 "The Metropolis and Mental Life", in: David Frisby and Mike Featherstone (eds.), Simmel on Culture: Selected Writings, London: SAGE, 174-185.

Sorabji, Richard 1983 Time, Creation and the Continuum: Theories in Antiquity and the Early Middle Ages, Ithaca, NY: Cornell University Press.

Sorokin, Pitirim A. and Merton, Robert K. 1937 "Social Time: A Methodological and Functional Analysis", American Journal of Sociology 42, 615-29.

Steininger, Christian 2005 "Time and Media Culture: Findings of Media and Communication Science", in: Friedrich Stadler and Michael Stöltzner (eds.), Time and History: Papers of the 28th International Wittgenstein Symposium, Kirchberg am Wechsel: ALWS, 290-292.

Townsend, A.M. 2000 "Life in the Real-Time City: Mobile Telephones and Urban Metabolism", Journal of Urban Technology 7, 85-104.

Whitrow, G.J. 1961 The Natural Philosophy of Time, London: Thomas Nelson.

Wittgenstein, Ludwig 1953 Philosophical Investigations, Oxford: Basil Blackwell.

- 1958 The Blue and Brown Books, Oxford: Basil Blackwell.

- 1975 Philosophical Remarks, transl. by Raymond Hargreaves and Roger White, Chicago: The University of Chicago Press.

- 1978 Remarks on the Foundations of Mathematics, transl. by G.E.M.Anscombe, Oxford: Basil Blackwell.

- 1979 Wittgenstein's Lectures: Cambridge, 1932-1935, ed. by Alice Am- 
brose, Oxford: Basil Blackwell.

Wittgenstein, Ludwig 2000 Nachlass: The Bergen Electronic Edition, Oxford: Oxford University Press.

- 2001 Philosophische Untersuchungen: Kritisch-genetische Edition, ed. by Joachim Schulte et al., Frankfurt am Main: Suhrkamp.

- 2005 The Big Typescript: TS 213, ed. and transl. by C. Grant Luckhardt and Maximilian A. E. Aue, Malden, MA: Blackwell Publishing. 